\title{
Returning to the Classroom Following Sport-Related Concussion: Perspectives of College Student Athletes
}

Amanda Acord-Vira

Follow this and additional works at: https://researchrepository.wvu.edu/etd

\section{Recommended Citation}

Acord-Vira, Amanda, "Returning to the Classroom Following Sport-Related Concussion: Perspectives of College Student Athletes" (2017). Graduate Theses, Dissertations, and Problem Reports. 5027.

https://researchrepository.wvu.edu/etd/5027

This Dissertation is protected by copyright and/or related rights. It has been brought to you by the The Research Repository @ WVU with permission from the rights-holder(s). You are free to use this Dissertation in any way that is permitted by the copyright and related rights legislation that applies to your use. For other uses you must obtain permission from the rights-holder(s) directly, unless additional rights are indicated by a Creative Commons license in the record and/ or on the work itself. This Dissertation has been accepted for inclusion in WVU Graduate Theses, Dissertations, and Problem Reports collection by an authorized administrator of The Research Repository @ WVU.

For more information, please contact researchrepository@mail.wvu.edu. 
Returning to the Classroom Following Sport-Related Concussion:

Perspectives of College Student Athletes

Amanda Acord-Vira, MOT, OTR/L

\author{
Dissertation submitted \\ to the College of Education and Human Services \\ at West Virginia University \\ in partial fulfillment of the requirements for the degree of \\ Doctor of Education in \\ Educational Psychology \\ Reagan Curtis, Ph.D., Chair \\ M. Cecil Smith, Ph.D. \\ Neal Shambaugh, Ph.D. \\ Patricia Haught, Ed.D. \\ Diana Davis, Ph.D., OTR/L \\ Steven Wheeler, Ph.D., OTR/L \\ Department of Learning Sciences and Human Development
}

Morgantown, West Virginia

2017

Keywords: sport-related concussion, return to learn, postsecondary, college Copyright 2017 Amanda Acord-Vira 


\author{
Abstract \\ Returning to the Classroom Following Sport-Related Concussion: \\ Perspectives of College Student Athletes
}

\begin{abstract}
Amanda Acord-Vira
The purpose of this study was to examine student athletes' perspectives in regard to return to learn following sport-related concussion. Data were collected through an online survey from student athletes; a subset of whom had a history of concussion. Student athletes who reported receiving education regarding the effects of concussion on classroom performance were more likely to report a concussion and receive accommodations for that concussion. Also, student athletes experiencing specific symptoms reported certain accommodations to be more or less beneficial with returning to the classroom following concussion. However, the presence of a return to learn policy at colleges did not improve the likelihood that student athletes received education on the effects of concussion on academic performance or improve concussion reporting and student athletes receiving accommodations while recovering from symptoms of concussion. Returning to the classroom prior to symptom resolution following concussion can have adverse effects on symptom recovery, learning, grades, and ultimately the livelihood of the student athletes. Colleges need to provide education specifically on the effect of concussion on classroom performance to increase the likelihood of student athletes reporting a suspected concussion to a school official. Student athletes who report concussion are more likely to receive accommodations when returning to the classroom that will enhance recovery without exacerbating symptoms.
\end{abstract}




\section{Table of Contents}

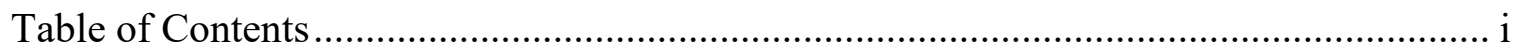

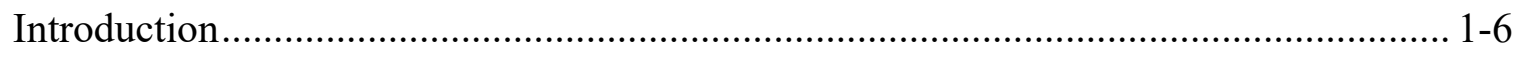

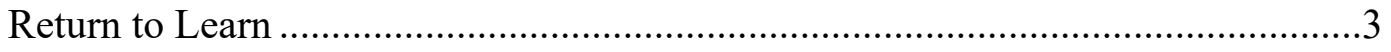

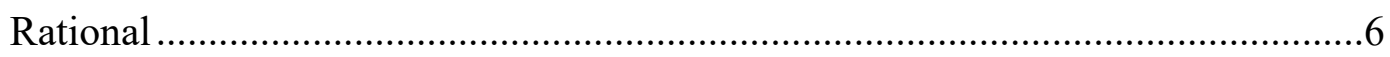

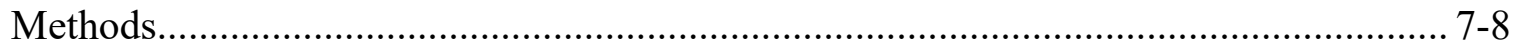

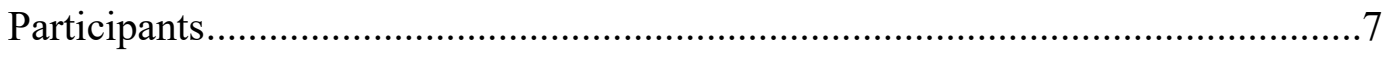

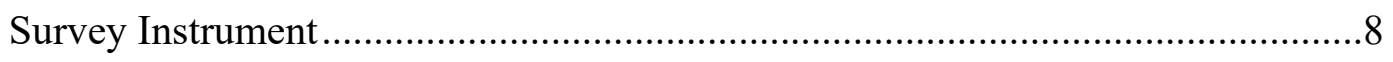

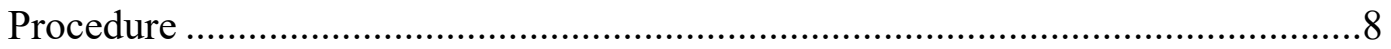

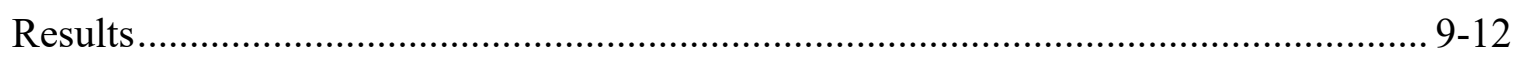

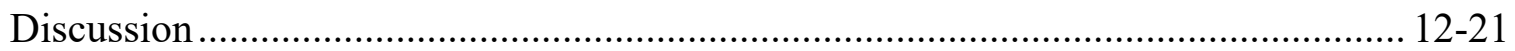

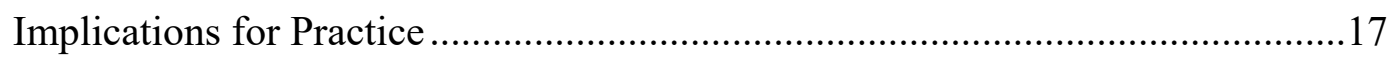

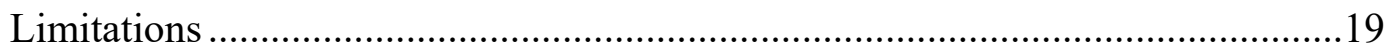

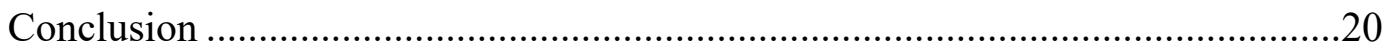

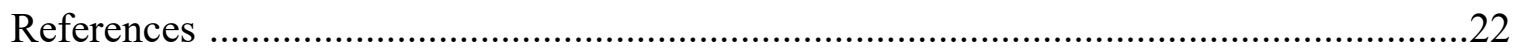

\section{List of Tables}

Table 1 Severity of Symptoms Reported by Participants Following SRC ......................28

Table 2 Student's Experiences of Returning to the Classroom Following Concussion ....29 
Returning to the Classroom Following Sport-Related Concussion:

Perspectives of College Student Athletes

Concussion is major public health concern in the United States is the incidence of concussion. According to the Centers for Disease Control \& Prevention (CDC), "a concussion is a type of traumatic brain injury -or TBI- caused by a bump, blow, or jolt to the head or by a hit to the body that causes the head and brain to move rapidly back and forth. This sudden movement can cause the brain to bounce around or twist in the skull, stretching and damaging the brain cells, and creating chemical changes in the brain" (CDC, 2015b). Sport-related concussion (SRC) is a subtype of mild traumatic brain injury (mTBI) that affects approximately 1.6 million to 3.8 million individuals each year (Langlois, Rutland-Brown \& Wald, 2006).

Concussion can cause alter brain function and affect memory and orientation (Giza et al., 2013; Harmon et al., 2013; McCrory et al., 2013a; West \& Marion, 2014). Students who experience a concussion can report a variety of symptoms, some of which interfere with learning. These symptoms may resolve quickly in a matter of days, or can take weeks or months to recover (Wasserman, Bazarian, Mapstone, Block, \& van Wijngaarden, 2016). Concussion symptoms that students experience can be classified into four categories: cognitive (e.g., thinking, memory, confusion, amnesia), physical (e.g., headache, dizziness, balance, sensory, nausea), emotional/mood (e.g., excess excitability or irritability, depression, anxiety), and sleep (e.g., insomnia, drowsiness; Brown, Elsass, Miller, Reed \& Reneker, 2015; CDC, 2015a; Gessel, Fields, Collins, Dick, \& Comstock, 2007).

Sport-related concussion has received a lot of attention over the last decade due to the public awareness campaigns and the long-term effects concussions can have on student athletes. Organizations such as the National Football League (NFL) and the National Collegiate Athletic Association (NCAA) have participated in the assessment, management, and prevention of 
SRC's, and also worked to increase awareness of the incidence and long-term effects of concussion (Bonds, Edwards, \& Spradley, 2014). There continues to be inconsistencies across colleges and sport associations regarding best care approaches and management of student athletes who sustain a concussion as well as compliance with recommended approaches.

To promote best practice, the NCAA adopted a Concussion Policy and Legislation in 2010 that affects athletes who play in NCAA regulated sports at colleges (Baugh et al., 2014). Colleges sanctioned by the NCAA must implement a concussion management plan that includes education on the symptoms of concussion, a process for the evaluation and management for student athletes experiencing symptoms of a concussion, a return to play (RTP) protocol, and a medical clearance policy to return to athletics. In 2017, the "Interassociation Consensus: Diagnosis and Management of Sport-Related Concussion Guidelines" was released following the 2014 Safety in College Football Summit that expanded the list of requirements that colleges with students participating in NCAA sports must follow (NCAA Sport Science Institute, 2017, p. 34). These additional requirements include pre-participation baseline testing, procedures for reducing exposure, and education that includes a policy on return to learn (RTL).

Colleges have several opportunities for students to play a sport for either a varsity, club or intramural team. The NCAA is the largest varsity sport association with approximately 1,200 institutions and 460,000 student athletes. Participation in club sports is quickly rising in popularity with an estimated two million college students playing some type of club sport (Pennington, 2008). Club sports are usually overseen by student activity associations which also oversee intramural sports on campus. Intramural or recreation leagues allow students to participate in a less organized team where students from the same institution play against each other. However, due to the lack of organization nationwide for club and intramural/recreation 
sports, concussion management guidelines are not always available, and these groups are not mandated to follow the concussion policy and management guidelines for students playing for varsity associations such as the NCAA.

A concussion management plan does not necessarily translate into adherence to the required components of that plan. Paddack and colleagues (2016) found 25\% compliance with pre-participation assessment or baseline testing and 34.5\% compliance with management guidelines. Lynall, Laudner, Mihalik, and Stanek (2013) found that less than half of the participants indicated using a variety of objective methods for baseline testing, return to play guidelines, physician recommendations, and player self-report to diagnose concussion. In addition, there is wide variability in the amount and type of education athletes receive resulting in limited evidence on effective approaches (Kroshus \& Baugh, 2016), and only a small decrease in self-reporting and intention to play while experiencing symptoms from concussion (Kroshus, Daneshvar, Baugh, Nowinski, \& Cantu, 2014). Despite the available guidelines and education for an SRC, $43.5 \%$ of athletes return to their sport too early and $44.7 \%$ return to the classroom before symptoms subside (Carson et al., 2014).

\section{Return to Learn}

Return to learn (RTL) is a protocol or policy that guides reintroduction of a student gradually into the classroom after sustaining a concussion. The majority of colleges do not have a RTL policy established for student athletes who sustain a concussion (Paddack, DeWolf, Covassin, \& Kontos, 2016). Returning to the classroom too early following concussion, while still experiencing symptoms, can have negative effects on the student's ability to perform at preinjury status and can affect grades and eligibility for play. RTL following a concussion should be of primary concern because of increased risk for long-term impairments with learning that can 
ultimately affect the student athlete's lifelong choices of careers and livelihood (Makdissi et al., 2013; Selassie et al., 2013; Yi, Padalino, Chin, Montenegro, \& Cantu, 2013).

Returning to the classroom can cause excessive strain on the processes of the brain that should be monitored and utilizing cognitive rest and classroom accommodations should be used to decrease the likelihood of symptoms worsening. Cognitive rest is usually recommended for the first 24-48 hours after injury when symptoms are most severe, but further research is needed to determine the duration and type of cognitive rest that is warranted after concussion to maximize recovery (Giza et al., 2013; Hall et al., 2015; Harmon et al., 2013; McCrory et al., 2013b). Avoiding activities that increase symptoms and getting plenty of sleep helps brain cells to heal (McAvoy, 2012). Those activities (e.g., computer, phone, tablet, video games, television, reading, schoolwork) that require attention, memory, processing speed, and cognitive flexibility initially should be restricted and reintroduced slowly as symptoms and tolerance improves (Hall et al., 2015; Master, Gioia, Leddy, \& Grady, 2012; Scorza, Raleigh, \& O’Connor, 2012).

Students who miss class are at risk of getting further behind, and the added stress and anxiety of being away from peers and trying to catch up once returning to class can worsen and prolong symptoms (Gibson, Nigrovic, O’Brien, \& Meehan, 2013).

A RTL policy provides a process by which a student athlete follows guidelines to gradually return to the classroom while recovering from symptoms of concussion. Currently, there is no consistent standardized process for RTL in the college classroom like there is for RTP (Harmon et al., 2013; Makdissi et al., 2013; West \& Marion, 2014). Suggested progression of activity for RTL is similar to RTP guidelines with no activity, gradual reintroduction of cognitive activity, homework before schoolwork, school re-entry, gradual reintegration into academics, and resumption of normal cognitive workloads (Hall et al., 2015; Master et al., 2012). Student 
athletes should continue some level of cognitive rest without symptoms worsening before moving on to the next phase of cognitive activity (Baker et al., 2014).

A gradual return to cognitive activity can be achieved by providing student athletes with temporary classroom accommodations allowing the student to attend class and participate as tolerable, while still obtaining all the material and increased time to complete the assignments and exams. Possible accommodations include meetings with the instructor, excused absences from class, rest breaks, extension of assignment and test deadlines, extended testing time, accommodation for light and noise sensitivity (e.g., sunglasses, hats with visors, turn down lights, quiet location, limiting extra noises), removal from activities requiring physical participation, readers for assignments and tests, note taker and/or tutor, quiet exam rooms, and preferential seating (Hall et al., 2015; Halstead et al., 2013; Makdissi et al., 2013; McGrath, 2010; Moser, Glatts, \& Schatz., 2012; Quinlin, Bates, \& Angell 2012; Trammell \& Hathaway, 2007). The amount and type of accommodations need to be flexible enough to ensure effectiveness (Hadley, 2005; Makdissi et al., 2013).

The accommodation process in place at most universities and colleges is not sufficient to appropriately accommodate for concussion because symptoms typically resolve in a matter of weeks before the traditional accommodation can be completed. Because of the timeline to implementation in the current accommodation process, students who want to receive accommodations for concussion must proceed without the support of disability services (Baker, Boland, \& Nowik, 2012). If RTL policies are in place at colleges, academic professionals (e.g., academic supports/disability services, therapists, faculty, counselors), in conjunction with the physician, can assess the student athlete following concussion to develop a plan utilizing accommodations and services to optimize the student's classroom performance (Hadley, 2005). 
Short-term accommodations can be provided for the student to succeed immediately after the concussion until full recovery has occurred.

\section{Rationale}

The majority of the literature available on returning to activity following SRC is in the realm of returning to play (RTP) in comparison to returning to learn (RTL). While almost half of institutions indicate having a RTP policy at their institution, only 30\% maintain that they follow the established concussion management policy at their institution for athletes following SRC (Paddack et al., 2016). The goal of a RTL policy is to establish a process the student athletes can follow and provide the tools (e.g., accommodations) necessary for resuming the role of student as compared to student athlete. In addition, there is limited evidence concerning the impact of $\mathrm{SRC}$ on academic performance and the use of accommodations to maximize performance. Student athletes requiring accommodations for school should not be allowed to return to play (RTP; McAvoy, 2012) until they can fully return to cognitive activity.

The following research questions were addressed with an online survey completed by student athletes: (1) What are NCAA and non NCAA student athlete perspectives on current practices (e.g., RTL policy, education, baseline testing) with RTL following SRC; (2) What are student athletes' perspectives on returning to the classroom following an SRC; (3) Are student athletes who were aware of a RTL policy or who received education on the effects of concussion on academic performance more likely to report a concussion and receive accommodations while recovering from concussion symptoms; and (4) Are student athletes who experience a specific symptom as a result of an SRC more likely to report a particular accommodation as more or less important for returning to the classroom. 


\section{Methods}

\section{Participants}

A total of 237 college student athletes responded to an online survey. The records of 22 of the participants were removed due to not completing any additional questions after indicating they played a sport at the college level. One participant was eliminated due to not meeting the inclusion criteria. The remaining 214 participants met the inclusion criteria of being over the age of 18 and enrolled in a minimum of one credit hour at a college. All were enrolled in colleges that met the Carnegie Classification of Institutions of Higher Education with "very high undergraduate," "high undergraduate," or "majority undergraduate," and "four-year, full-time." Participants included 86 males and 128 females, and the ages ranged from 18 to 28 years of age with an average age of 20 years. The participants included freshman $(n=45,21.0 \%)$, sophomores $(n=59,27.6 \%)$, juniors $(n=49,22.9 \%)$, seniors $(n=49 ; 22.9 \%)$, and graduate $(n=12,5.61 \%)$ students who participated in a sport $(n=213)$ through either a club $(n=99,46.3 \%)$, NCAA $(n=97$, $45.3 \%)$, NAIA $(n=12,5.6 \%)$, or intramural/recreation sport $(n=5,2.3 \%)$. One student did not answer the question on sport association.

The student athletes who reported sustaining a concussion $(n=31)$, and who completed the survey, sustained one $(n=19,61.3 \%)$, two $(n=5,16.1 \%)$, or three or more $(n=7,22.6 \%)$ concussions while playing sports at the college level. These responses provided an avenue to investigate student athletes' perspectives on RTL guidelines, common symptoms experienced after SRC, and accommodations that may be important for returning to the classroom following an SRC. 


\section{Survey Instrument}

An online survey was developed to gain information from student athletes regarding RTL and the use of accommodations following concussion. The survey included 16 multiple choice, 2 Likert type items, and 2 open-ended questions. The survey took approximately ten minutes to complete. Any participants who indicated they were not a student athlete were immediately exited from the survey. The survey consisted of three sections: demographics, current practices with RTL, and experiences of returning to the classroom following SRC. The RTL section was completed by all participants and contained questions on the presence of a RTL policy, education on effects of SRC on academic performance, and baseline testing. Only student athletes who reported sustaining a concussion completed the final section of the survey. This section included questions related to experiences of returning to the classroom (e.g., recovery time, missed class days, accommodations received).

\section{Procedure}

An IRB was submitted, and approval gained prior to selection of participants. Four hundred and seven colleges met the Carnegie Classification of Institutions of Higher Education as listed above and were selected to distribute the online survey to the student athletes at that college. The Carnegie Classification of Institutions of Higher Education is a framework for describing colleges in the United States in terms of diversity and identify similarities or differences between institutions (Indiana University Center for Postsecondary Research, n.d.). The Carnegie Classifications were selected that would maximize the number of undergraduates because the majority of student athletes participate at the undergraduate level (NCAA, n.d). Emails were gathered from the internet for athletic directors, club sports and intramural/recreation leadership. The identified directors and leaders of the various sports were 
asked to send out the survey link and cover letter to student athletes at the institution. Reminder emails were sent twice following the initial contact.

\section{Results}

IBM SPSS 25 was used to analyze the data. Descriptive statistics and Fisher's Exact Test were run to answer research question (1), what are NCAA and non-NCAA student athlete perspectives on current practices (e.g., RTL policy, education, baseline testing) with RTL following SCR? Student athletes $(n=214)$ were surveyed and $78(36.4 \%)$ were aware of an available RTL policy, 91 (42.5\%) received education on the effects of SRC on academic performance, and 99 received baseline testing (46.3\%). NCAA student athletes $(n=97,45.3 \%)$ were compared to non-NCAA (e.g., club, intramural/recreation, NAIA) sport athletes $(n=116$, $54.5 \%$ ) to further describe current trends with RTL. Based on an odd's ratio to determine the effect size for variables found to be significant using the Fisher's Exact Test $(p<.05)$, NCAA student athletes were 4 times (95\%; CI: 2.21, 7.23) more likely to report awareness of an RTL policy, 2.91 times $(95 \%$; CI: 1.66, 5.12) more likely to report awareness of receiving education on the effects of SRC on academic performance, and 6.72 times $(95 \%$; CI: 3.68, 12.27) more likely to report receiving baseline testing than non-NCAA sport athletes.

The remaining research questions were assessed without comparison between sport associations due to the low response rate of student athletes reporting a history of concussion: NCAA $(n=9,29 \%)$, NAIA $(n=1,3.2 \%)$, club $(n=19,61.3 \%)$, intramural/recreation $(n=2,6.5 \%)$. Descriptive statistics were run to answer research question (2), what are student athletes' perspectives on returning to the classroom following an SRC? The student athletes who indicated a history of concussion $(n=31,14.5 \%)$ were surveyed about reporting of concussion symptoms and receiving classroom accommodations. The highest percentage of physical 
symptoms experienced by student athletes following SRC included headaches $(n=31,100 \%)$, dizziness $(n=27,87.1 \%)$, sensitivity to light $(n=25,80.6 \%)$, and feeling slowed $(n=24,77.4 \%)$.

Over $70 \%$ of the student athletes experienced symptoms in all areas of cognition including difficulty concentrating ( $n=25,80.6 \%)$, mentally foggy $(n=24,77.4 \%)$, and difficulty remembering $(n=22,71 \%)$. Table 1 displays frequency and percentages of all symptoms reported by the participants following their most recent concussion and the median level of severity on a 5-point scale.

Twenty-three (74\%) student athletes with a history of concussion reported symptoms to at least one or more of the following individuals: coach $(n=17,54.8 \%)$, family $(n=15,48.4 \%)$, physician $(n=15,48.4 \%)$, athletic trainer $(n=14,45.2 \%)$, teammate $(n=11,35.5 \%)$, faculty $(n=9$, $29.0 \%)$, or academic support/disability office $(n=1,3.2 \%)$. Twenty-eight student athletes $(90 \%)$ reported a recovery period of more than one day, but nineteen $(61.3 \%)$ participants did not miss any days of class. Concerning accommodations, $48 \%$ of the student athletes reported using accommodations while recovering from concussion. The most common classroom accommodations used after SRC were excused absences $(n=11,35.5 \%)$ and extension of tests and assignments $(n=9,29 \%)$. See Table 2 for more details on reported recovery time, days missed from school, and the availability and types of accommodations provided during their recovery following concussion.

Fisher's Exact Tests and odds ratios were run to answer research question (3), are student athletes who were aware of a RTL policy or received education on the effects of concussion on academic performance more likely to report a concussion and receive accommodations while recovering from concussion symptoms? A 2x2 contingency table was used with all variables as "Yes" or "No" for each comparison. Fisher's Exact Test confirmed that students with a history of 
concussion who are aware of a RTL policy at their institution were not significantly $(\mathrm{p}>.05)$ more likely to be aware of receiving education on concussion, report a concussion, or receive accommodations than student athletes with a history of concussion who do not report having a RTL policy. However, further analyses on the education component of the RTL policy confirmed that students receiving education on the impact of concussion on academic performance prior to the start of the season were significantly $(p<.05)$ more likely to report a concussion and receive accommodations than students who did not receive the same education. Student athletes with a history of concussion who received education on the impact of concussion on academic performance were 22.5 times (95\%; CI: $2.32,218.35)$ more likely to use accommodations and 1.62 times $(95 \%$; CI: 1.16, 2.26) more likely to report a concussion than those students who did not receive education on SRCs.

The Fisher's Exact Test and odds ratios were used to assess research question (4), are student athletes who experience a specific symptom as a result of an SRC more likely to report an accommodation as more or less important for returning to the classroom? Odds rations for statistically significant $(\mathrm{p}<.05)$ revealed that students who experienced fatigue were 7 times (95\%; CI: $1.36,35.93)$ more likely to report that a reader or note taker would be a valuable accommodation and student athletes reporting trouble falling asleep were 7.6 times (95\%; CI: 1.07, 54.09) more likely to report preferential seating as an important accommodation for returning to the classroom. Conversely, students who experienced headaches were 1.4 times (95\%; CI: $1.01,1.95)$ less likely to report an excused absence as an important accommodation for returning to the classroom. Students with vision problems were 2.9 times $(95 \%$; CI: 1.70 , 4.90) less likely to report rest breaks as an important accommodation for returning to the classroom and students feeling more emotional were 9.5 times $(95 \% ; 1.27,71.43)$ less likely to 
report wearing sunglasses or decreasing lighting as an important accommodation for returning to the classroom. Lastly, students sleeping more than usual were 1.4 times $(95 \% ; 0.21,9.35)$ less likely to report preferential seating as important for managing symptoms to return to the classroom following SRC.

\section{Discussion}

Despite the advances made in the assessment and management of SRC, there is still limited research regarding student athletes' academic experiences during the recovery period. The purpose of this study was to examine student athletes' perspectives of RTL following SRC. Less than half of the student athletes surveyed reported awareness or knowledge of several key components of a concussion management policy. However, student athletes who participated in NCAA sanctioned sports were more likely to be aware of a RTL policy, receive education on the effects of concussion on academic performance, and participate in baseline testing. In addition, NCAA athletes were less likely to report history of a concussion than students who participated in a club sport. Further research is warranted to determine if the differences between NCAA and club athletes is due to the effectiveness of the NCAA's concussion management plan.

Despite the growing trend that colleges adopt a RTL policy or classroom guidelines for learning after concussion, the results from this study indicate that only one-third of student athletes reported being aware of a RTL policy at their institution. This is consistent with the findings by Paddack and colleagues (2016), who found only $31 \%$ of athletic trainers surveyed had academic accommodation policies at the institutions they worked. This finding is problematic because many athletes are attending colleges that may not have a RTL policy in place to follow after sustaining an SRC unless the student participates in a NCAA sanctioned 
sport. Even if the college has a policy in place, student athletes may not be aware of the policy or may not be compliant with the recommendations in spite of their awareness.

Student athletes with a history of concussion who were aware of a RTL policy at their institution were not more likely than students who were not aware of a RTL policy to receive education on the impact of concussion on academic performance, report a concussion, or receive accommodations while recovering. Simply having a RTL policy for returning to the classroom following concussion does not necessarily improve the knowledge or experiences of student athletes who sustain a concussion. Since $44.7 \%$ of student athletes with a concussion return to the classroom before symptoms subside (Carson et al, 2014), the goal should be to provide information on the existence and purpose of a RTL policy. This includes education on the impact of concussion on classroom performance and to improve awareness of resources available following concussion.

A concussion management policy should include education for student athletes. Kroshus and Baugh (2016) found that $80 \%$ of students surveyed reported receiving some form of education on concussion in general from colleges. However, individual institutions determine the amount and content of the education material provided to student athletes. Institutions may or may not choose to cover content regarding the effects of concussion on academic performance. In this study, only $43 \%$ of student athletes reported receiving education specifically on the impact of SRC on academic performance. Kroshus and Baugh (2016), found that $86 \%$ of student athletes reported wanting more education on the impact of concussion on academic performance.

A RTL policy should provide an avenue for specific education on the effects of concussion on academic performance to be developed and implemented to improve awareness. 
Student athletes who indicated that they had received education on the effects of concussion on academic performance were more likely to report a concussion and more likely to receive accommodations. Findings from the current study support the benefits of equipping students with knowledge of the consequences of concussion on academic performance. Improving participation in school following an SRC may be achieved by providing a supportive environment and concussion knowledge to collegiate athletes. This may facilitate symptom reporting to school professionals and requesting appropriate accommodations that can promote RTL.

Most of the literature available has focused on RTP, not on returning to the classroom following concussion. In this study, over $80 \%$ of the student athletes with a history of concussion reported a recovery time of less than 2 weeks. In addition, $61 \%$ of student athletes reported missing zero days of school. Student athletes may be returning to the classroom prior to their symptoms resolving. This could have negative effects on their ability to learn and on their grades as well as possibly lengthening their recovery. The majority of student athletes in the current study indicated difficulty concentrating and remembering as a result of concussion. Even though students reported symptoms for weeks and still attended class, less than half received any accommodations.

Providing a graduated plan with appropriate accommodations to return students to the classroom should promote recovery and provide opportunities for learning simultaneously. Accommodations need to be individualized to the student's specific needs based on the types of symptoms experienced during the recovery period and the type of college courses enrolled. The most common accommodations received by over $30 \%$ of student athletes in this study were excused absences and extensions for tests and assignments. This is consistent with Paddack and 
colleagues (2016), who found that the two most common accommodations provided by colleges were excused absences and extended learning time.

There are several recommended accommodations for student athletes returning to the classroom following SRCs (Hall et al., 2015; Halstead et al., 2013; Makdissi et al., 2013; McGrath, 2010; Moser et al., 2012; Quinlin et al., 2012; Trammell \& Hathaway, 2007). However, there is limited research on perceived benefits or importance of these accommodations from college athletes' perspectives. In an ideal situation, students who report a specific symptom will then receive an accommodation that is beneficial for managing that symptom upon returning to the classroom.

In this study, student athletes perceived several accommodations as either important or not important for managing a variety of symptoms when returning to the classroom following an SRC. Students reporting fatigue were more likely to perceive a reader or note taker as an important accommodation for returning to the classroom. The demands of returning to the classroom are complex and require students to be able to multitask (e.g., listen while taking notes). Engaging in multiple activities may increase fatigue, causing students to become exhausted and interfere with their ability to fully participate in school related activities (Birgitta \& Lars, 2017) and the use of a note taker or reader will decrease the amount of multitasking required of a student in the classroom setting.

Approximately $50 \%$ of student athletes with a history of concussion in this study reported having trouble falling asleep or sleeping more than usual. Sleep disturbances following SRC can have an impact on symptom reporting and cognitive functioning (Kostyun, Milewski, Hafeez, 2014; McClure, Zuckerman, Gregory, Kutscher, \& Solomon, 2013; Mihalik et al., 2013). Sleep is often assessed through self-reporting of hours slept and quality of sleep. Sleep disturbances 
can increase symptom reporting as well as recovery time. Student athletes in this study who reported difficulties with sleeping perceived the accommodation of preferential seating as important for the symptom of having trouble falling asleep and unimportant for sleeping more than usual. Preferential seating (e.g., sitting closer to the instructor, sitting away from distractions; close/farther away sensory items in the room; Byrnes, 2008) may provide students a location in the classroom to be seated that meets their needs based on the type of sleeping symptoms experienced and thereby promote learning.

Headaches are one of the most common symptoms of concussion and experienced by all student athletes in this study. Student athletes reported that excused absences were not an important accommodation for recovery of concussion, which is evident by the majority of students not missing any days. As one student reported, "It was hard to miss class and have to catch up when coming back." Gibson and colleagues (2013) found that the fear of getting behind by missing class could worsen and prolong symptoms. As research on cognitive rest progresses, students may require education on the benefits of limited excused absences to manage symptoms.

Vision and emotion symptoms also affected a sizable portion of student athletes following an SRC in this study. There was an association between students reporting visual problems and the accommodation of rest breaks. Simply providing a rest break was reported as not an important accommodation for student athletes to return to the classroom. Also, students reporting more emotional distress after the concussion felt that lowering the lighting or wearing sunglasses would not be helpful for returning to the classroom. Students who experience emotional problems in combination with decreased visual memory may be more likely to use avoidance coping (Covassin, Elbin, Crutcher, Burkhart, \& Kontos, 2013). Avoidance coping is 
when an individual tries to escape or ignore a problem or unwanted situation. However, in the long-term, avoidance coping is associated with higher levels of psychological distress and poor adjustment (Wood \& Doughty, 2013). In this study, over 50\% of participants indicated feeling more emotional after their concussion. There is little literature on specific accommodations that can be used to address visual and emotional symptoms in the classroom following SRC. Further research and analysis identifying appropriate accommodations for visual (e.g., inability to focus, double vision, visually alternate between or follow objects; Master et al., 2016) and emotional symptoms will allow students to engage in learning while maximizing performance without worsening symptoms.

\section{Implications for Practice}

There is a lack of awareness among many student athletes regarding RTL policies. The purpose of a RTL policy is to provide students with knowledge of what to do after experiencing an SRC, how and to whom to report an SRC, and how to seek assistance when returning to the classroom. The majority of student athletes in this study were unaware whether a RTL policy at their institution was available to help them navigate the process of recovering from concussion. Even when students were aware of a RTL policy, it appeared that the presence of such a policy had little effect on student behavior (e.g., regarding reporting and pursuing appropriate accommodations) unless the policy included education on the impact of SRC on classroom performance. The NCAA's concussion management plan appears to be making a difference with awareness of policies and services available by student athletes. In addition, NCAA student athletes reported lower incidence of SRC than club sports. Sport associations that currently do not have RTL policy in place or are not in compliance, should consider developing and implementing guidelines for RTL and providing education to student athletes on the effects of 
concussion on academic performance. Implementing RTL policy may decrease the effects that concussion has on learning, grades (e.g., lower GPA, failing), and future goals (e.g., unable to attend graduate school or professional program due to low GPA, inability to finish school due to failing a course).

Education is significantly associated with students reporting and receiving accommodations following SRC. Colleges should provide concussion education prior to the beginning of the sport season. This is an effective strategy to increase the likelihood of student athletes reporting a suspected concussion to a school official. Only when student athletes report a suspected concussion can academic professionals then provide necessary services and supports that will enhance recovery from concussion. Student athletes in this study perceived several accommodations as important or not important for their returning to the classroom after experiencing a specific symptom of concussion. Obtaining classroom accommodations can be time intensive and complicated, resulting in accommodations not being available until after concussion symptoms have resolved. A process for obtaining short-term accommodations following a diagnosis of concussion should be implemented with a RTL policy at all colleges, as this would be helpful to both athletes and non-athletes.

College faculty and staff have an obligation to assist student athletes with understanding and following the institution's RTL policy. Collaboration is needed between the Office of Disability Services and other academic professionals (e.g., faculty, occupational therapist, advisor), who are experts in learning, to develop a checklist of symptoms that correspond to appropriate accommodations to simplify the process and ensure students are receiving only the accommodations that are essential for learning when returning to the classroom. School professionals would use the checklist when a student athlete reported a concussion to determine 
the appropriate accommodations to use for the gradual return to the classroom. More research is needed to inform the creation of this checklist.

Future research should focus on investigating concussion management plans to determine the components that are most effective at decreasing the incidence of concussion while increasing reporting rates, use of accommodations, and student athletes' awareness of policies and services available to them. In addition, future research should assess perceived benefits of accommodations for specific symptoms on a larger scale and with objective measures in addition to self-report of student athletes recovering from concussion. This will assist with the development of short-term accommodations that would be beneficial for returning to the classroom. This list needs to be inclusive of accommodations important for symptom management, but selective enough to exclude accommodations that are not important for symptom management when returning to the classroom. Finally, future studies should assess the amount and types of education that should be provided to various members of the multidisciplinary school professionals to ensure they are trained and educated on the symptoms of concussion and best practice approaches for management of SRC.

\section{Limitations}

Only student athletes representing colleges in the Carnegie Classification of Institutions of Higher Education with "very high undergraduate," "high undergraduate," or "majority undergraduate," and "four-year, full-time students participated in this study. These institutions were selected because they enroll predominantly undergraduate students who are eligible to play sanctioned sports. However, this is a limitation because the results may not be generalizable to other classifications of postsecondary institutions. This study had a low response rate that may be due to the timing of the survey delivery (e.g., summer session, during busy times of semester) 
and lack of interest in participation by students and institutions (e.g., schools not wishing to participate due to topic, no time, too many survey requests, perceived legal risk). This study used self-report of student athletes rather than objective measures of performance (e.g., learning, grades) to evaluate accommodations assumed to be beneficial for returning to the classroom.

\section{Conclusion}

When student athletes return to the classroom too soon following concussion, they may experience any of a number of negative consequences. These include prolonged symptom recovery, difficulty learning, and lower grades. While there has been considerable attention on athletes RTP, there has been limited research regarding student athletes RTL following sports related concussion. Providing students with RTP and RTL policies following diagnosis of concussion should also include education on the effects of concussion. In the study reported here, education was found to be significantly related to the likelihood of reporting and using accommodations after concussion. Having only a policy on RTL without corresponding education was not associated with reporting of concussion or using accommodations. Having a graduated plan for returning to the classroom following concussion can enhance student athletes' recovery and assist their academic performance. A major component of a graduated plan is provision of short-term accommodations during recovery. Short-term accommodations may include classroom modifications (e.g., accommodation for light and noise sensitivity, removal from activities requiring physical participation, quiet exam rooms, preferential seating), assistance from others (e.g., meetings with instructor, tutor, readers and note takers for tests and assignments), time extensions for testing and assignments, rest breaks, and excused absences (Hall et al., 2015; Halstead et al., 2013; Makdissi et al., 2013; McGrath, 2010; Moser et al., 2012; Quinlin et al., 2012; Trammell \& Hathaway, 2007). The effects of a concussion can have 
negative effects on student athletes' learning and classroom success and implementing policies that include graduated plans with accommodations that promote recovering is essential for student athletes to continue to learn and be successful in the classroom as symptoms subside. 


\section{References}

Baker, J. G., Rieger, B. P., McAvoy, K, Leddy, J. J., Master, C. L., Lana, S. J., \& Willer, B. S. (2014). Principles for return to learn after concussion. International Journal of Clinical Practice, 68(11), 1286-1288. doi:10.1111/ijcp.12517

Baker, K. Q., Boland, K., \& Nowik, C. M. (2012). A campus survey of faculty and student perceptions of persons with disability. Journal of Postsecondary Education and Disability, 25(4), 309-329.

Baugh, C. M., Kroshus, E., Daneshvar, D. H., Filali, N. A., Hiscox, M. J., \& Glantz, L. H. (2014). Concussion management in United States college sports: Compliance with National Collegiate Athletic Association concussion policy and areas for improvement. The American Journal of Sports Medicine, 43(1), 47-56. doi:10.1177/0363546514553090

Birgitta, J., \& Lars, R. (2017). Assessment and treatment of mental fatigue after a traumatic brain injury. Neuropsychological Rehabilitation, 27(7), 1047-1055.

Bonds, G. B., Edwards, W. W., \& Spradley, B. D. (2014). Advancements in concussion prevention, diagnosis, and treatment. The Sport Journal, 17.

Brown, D. A., Elsass, J. A., Miller, A. J., Reed, L. E., \& Reneker, J. C. (2015). Differences in symptom reporting between males and females at baseline and after a sports-related concussion: A systematic review and meta-analysis. Sports Medicine, 45, 1027-1040. doi:10.1007/s40279-015-0335-6

Byrnes, M. (2008). Educators' interpretations of ambiguous accommodations. Remedial and Special Education, 29(5), 306-315. doi: 10.1177/0741932507313017

Carson, J. D., Lawrence, D. W., Kraft, S. A., Garel, A., Snow, C. L., Chatterjee, A., ... Frémont, 
P. (2014). Premature return to play and return to learn after a sport-related concussion. Canadian Family Physician, 60, 310-315.

Centers for Disease Control and Prevention. (2015a). Injury prevention \& control: Traumatic Brain Injury \& Concussion. Retrieved February 28, 2015, from $\underline{\text { http://www.cdc.gov/TraumaticBrainInjury/index.html }}$

Centers for Disease Control and Prevention (2015b). Heads Up. Retrieved February 28, 2015 from www.cdc.gov/headsup/basics/concussion_whatis.html

Covassin, T., Elbin, R. J., Crutcher, B., Burkhart, S., \& Kontos, A. (2013). The relationship between coping, neurocognitive performance, and concussion symptoms in high school and collegiate athletes. The Sport Psychologist, 27, 372-379.

Gessel, L. M., Fields, S. K., Collins, C. L., Dick, R. W., \& Comstock, R. D. (2007). Concussion among United States high school and collegiate athletes. Journal of Athletic Training, 42(4), 495-503.

Gibson, S., Nigrovic, L. E., O’Brien, M., \& Meehan, W. P. (2013). The effect of recommending cognitive rest on recovery from sports-related concussion. Brain Injury, 27(7-8), 839842. doi:10.3109.02699052.2013.775494

Giza, C. C., Kutcher, J. S., Ashwal, S., Barth, J., Getchius, T. S., Gioia, G. A., ...Zafonte, R. (2013). Summary of evidence-based guideline update: Evaluation and management of concussion in sports: Report of the guideline development subcommittee of the American Academy of Neurology. Neurology, 80, 2250-2257.

Hadley, W. M. (2005). The importance of school choice for college-bound students with learning disabilities. National Association for College Admission Counseling, 43(2), 18 19. 
Hall, E. E., Ketchum, C. J., Crenshaw, C. R., Baker, M. H., McConnell, J. M., \& Patel, K. (2015). Concussion management in collegiate student-athletes: Return-to-academics recommendations. Clinical Journal of Sports Medicine, 25(3), 291-296.

Halstead, M. E., McAvoy, K., Devore, C. D., Carl, R., Lee, M., Logan, K., ...\& Council on School Health. (2013). Returning to learning following a concussion. American Academy of Pediatrics, 132, 948-957. doi:10.1542/peds.2013-2867

Harmon, K., Drezner, J., Gammons, J., Guskiewicz, K., Halstead, M., Herring, S., ...Roberts, W. (2013). American Medical Society for Sports Medicine position statement: Concussion in sport. Clinical Journal of Sports Medicine, 23, 1-18.

Indiana University Center for Postsecondary Research (n.d.). The Carnegie Classification of Institutions of Higher Education, 2015 edition, Bloomington, IN: Author.

Kostyun, R. O., Milewski, M. D., \& Hafeez, I. (2014). Sleep disturbances and neurocognitive function during the recovery from a sport-related concussion in adolescents. The American Journal of Sports Medicine, 43(3), 633-640. doi:10.1177/0363546514560727

Kroshus, E., \& Baugh, C. M. (2016). Concussion education in U.S. collegiate sports: What is happening and what do athletes want? Health Education \& Behavior, 43(2), 182-190. doi:10.1177/1090198115599380

Kroshus, E., Daneshvar, D. H., Baugh, C. M., Nowinski, C. J., \& Cantu, R. C. (2014). NCAA concussion education in ice hockey: An ineffective mandate. British Journal of Sports Medicine, 48, 135-140. doi:10.1136/bjsports-2013-092498

Langlois, J. A., Rutland-Brown, W., \& Wald, M. M. (2006). The epidemiology and impact of traumatic brain injury: A brief overview. Journal of Head Trauma Rehabilitation, 21(5), $375-378$. 
Lynall, R. C., Laudner, K. G., Mihalik, J. P., \& Stanek, J. M. (2013). Concussion-assessment and management techniques used by athletic trainers. Journal of Athletic Training, 48(6), 844-850.

Makdissi, M., Davis, G., Jordan, B., Patricios, J., Purcell, L., \& Putukian, M. (2013). Revisiting the modifiers: How should the evaluation and management of acute concussions differ in specific groups? British Journal of Sports Medicine, 47(3), 314-320.

doi:10.1136/bjsports-2013-092256

Master, C. L., Scheiman, M., Gallaway, M., Goodman, A., Robinson, R., Master, S., \& Grady, M. (2016). Vision diagnoses are common after concussion in adolescents. Sage Journals, 55, 260-267. doi.org/10.1177/0009922815594367

Master, C. L., Gioia, G. A., Leddy, J. J., \& Grady, M. F. (2012). Importance of 'return-to-learn' in pediatric and adolescent concussion. Pediatric Annals, 41(9), 1-6.

McAvoy, K. (2012, March/April). Return to learning: Going back to school following a concussion. Communique, 40(6), 1, 23-25.

McClure, D. J., Zuckerman, S. L., Kutscher, S. J., Gregory, A. J., \& Solomon, G. S. (2013). Baseline neurocognitive testing in sports-related concussions: The importance of a prior night's sleep. The American Journal of Sports Medicine, 42(2), 472-478. doi:10.1177/0363546513510389

McCrory, P., Meeuwisse, W., Aubry, M., Cantu, B., Dvorak, J., Echemendia, R., ...Turner, M. (2013a). Consensus statement on concussion in sport: The $4^{\text {th }}$ International Conference on Concussion in Sport held in Zurich, November 2012. British Journal of Sports Medicine, 47, 250-258.

McCrory, P., Meeuwisse, W. H., Echemendia, R. J., Iverson, G. L., Dvorak, J., \& Kutcher, J. S. 
(2013b). What is the lowest threshold to make a diagnosis of concussion? British Journal of Sports Medicine, 47, 268-271. doi:10.1136/bjsports-2013-092247

McGrath, N. (2010). Supporting the student-athlete's return to the classroom after a sport-related concussion. Journal of Athletic Training, 45(5), 492-498.

Mihalik, J. P., Lengas, E., Register-Mihalik, J. K., Oyama, S., Begalle, R. L., \& Guskiewicz, K. M. (2013). The effects of sleep quality and sleep quantity on concussion baseline assessment. Clinical Journal of Sport Medicine, 23(5), 343-348.

Moser, R. S., Glatts, C., \& Schatz, P. (2012). Efficacy of immediate and delayed cognitive and physical rest for treatment of sports-related concussion. The Journal of Pediatrics, 161(5), 922-926. doi:10.1016/j.peds.2012.04.012

National Collegiate Athletic Association. (n.d.). Eligibility Timeline. Retrieved on November 30, 2017 from http://www.ncaa.org/student-athletes/current/transfer-terms.

NCAA Sport Science Institute (2017). Interassociation consensus: Diagnosis and management of sport-related concussion best practices. Retrieved on October 31, 2017 from http://www.ncaa.org/sites/default/files/SSI_ConcussionBestPractices_20170616.pdf

Paddack, M., DeWolf, R., Covassin, T., \& Kontos, A. (2016). Policies, procedures, and practices regarding sport-related concussion in community college athletes. Journal of Athletic Training, 51(1), 82-88. doi:10.4085/1062-6050-51.2.01

Pennington, B. (2008, December 1). Rise of college club teams creates a whole new level of success. The New York Times. Retrieved on June 2, 2016, from http://www.nytimes.com/2008/12/02/sports/02club.html?_r=0

Quinlin, M. M., Bates, B. R., \& Anell, M. E. (2012). 'What can I do to help?': Postsecondary 
students with learning disabilities' perceptions of instructors' classroom accommodations. Journal of Research in Special Education Needs, 12(4), 224-233.

Scorza, K. A., Raleigh, M. F., \& O’Connor, F. G. (2012). Current concepts in concussion: Evaluation and management. American Family Physician, 85(2), 123-132.

Selassie, A. W., Dulaney, A. W., Pickelsimer, E. E., Voronca, D. C., Williams, N. R., \& Edwards, J. C. (2013). Incidence of sport-related traumatic brain injury and risk factors of severity: A population-based epidemiologic study. Annals of Epidemiology, 23, 750-756. http://dx.doi.org/10.1016/j.annepidem.2013.07.022

Trammell, J., \& Hathaway, M. (2007). Help-seeking patterns in college students with disabilities. Journal of Postsecondary Education and Disability, 20(1), 5-15.

Wasserman, E. B., Bazarian, J. J., Mapston, M., Block, R., \& van Wijngaaarden (2016). Academic dysfunction after a concussion among US high school and college students. American Journal of Public Health, 106(7), 1247-1253.

West, T. A., \& Marion, D. W. (2014). Current recommendations for the diagnosis and treatment of concussion in sport: A Comparison of three new guidelines. Journal of Neurotrauma, 31, 159-168. doi:10.1089/neu.2013.3031

Wood, R. L., \& Doughty, C. (2013). Alexithymia and avoidance coping following traumatic brain injury. Journal of Head Trauma Rehabilitation, 28(2), 98-105.

Yi, J., Padalino, D. J., Chin, L. S., Montenegro, P., \& Cantu, R. C. (2013). Chronic Traumatic Encephalopathy. Current Sports Medicine Reports, 12(1), 28-32. 
Table 1

Severity of Symptoms Reported by Participants Following SRC ( $n=31)$

\begin{tabular}{lccc}
\hline & Frequency & Percent & Median \\
\cline { 2 - 3 } Physical & & & \\
Headache & 31 & 100 & 3 \\
Dizziness & 27 & 87.1 & 2 \\
Sensitivity to Light & 25 & 80.6 & 2 \\
Feeling Slowed & 24 & 77.4 & 2 \\
Fatigue & 22 & 71.0 & 3 \\
Sensitivity to Noise & 22 & 71.0 & 2 \\
Balance Problems & 20 & 64.5 & 1 \\
Visual Problems & 18 & 58.1 & 1.5 \\
Nausea & 17 & 54.8 & 2 \\
Numbness/Tingling & 11 & 35.5 & 1 \\
Vomiting & 8 & 25.8 & 1 \\
Cognitive & & & \\
Difficulty Concentrating & 25 & 80.6 & 3 \\
Mentally Foggy & 24 & 77.4 & 2.5 \\
Difficulty Remembering & 22 & 71.0 & 2 \\
Emotional & & & \\
Irritability & 21 & 67.7 & 1 \\
Sadness & 17 & 54.8 & 1 \\
Feeling more emotion & 17 & 54.8 & 2 \\
Nervousness & 15 & 48.4 & 1 \\
Sleep & & & \\
Drowsiness & 21 & 67.7 & 2 \\
Trouble falling asleep & 18 & 58.1 & 2 \\
Sleeping more than usual & 14 & 45.2 & 2 \\
Sleeping less than usual & 12 & 38.7 & 1 \\
\hline Note: & & & \\
\hline
\end{tabular}

Note: $0=$ did not experience symptom, $1=$ barely noticed symptom, $2=$ clearly noticed, but could behave normally, $3=$ symptom bad enough to make normal behavior difficult, $4=$ symptom bad enough to make normal behavior impossible; Symptoms based off the Post Concussion Symptom Scale. 
Table 2

Student's Experiences of Returning to the Classroom Following Concussion (n=31)

\begin{tabular}{lcc}
\hline & Frequency & Percent \\
\cline { 2 - 3 } Recovery Time & 3 & 9.7 \\
1 day or less & 10 & 32.3 \\
2-5 days & 6 & 19.4 \\
5-6 days & 8 & 25.8 \\
1-2 weeks & 2 & 6.5 \\
3-4 weeks & 2 & 6.5 \\
More than 1 month & & \\
& & \\
Missed Class & 19 & 61.3 \\
0 days & 8 & 25.8 \\
1-3 days & 2 & 6.5 \\
4-6 days & 2 & 6.5 \\
1-2 weeks & 0 & 0 \\
3-4 weeks & 0 & 0 \\
More than 1 month & & \\
& & \\
Accommodations Received & 11 & 35.5 \\
Excused Absences & 4 & 12.9 \\
Rest Breaks & 9 & 29.0 \\
Extensions tests/assignments & 1 & 3.2 \\
Extended time for tests & 1 & 3.2 \\
Sunglasses/reduced lighting & 0 & 0 \\
Quiet Room & 1 & 3.2 \\
Reader/Note taker & 0 & 0 \\
Preferential Seating & 1 & \\
Tutor & & \\
\hline
\end{tabular}

Note: Recovery Time=the number of days the student athlete reported before being symptom free following concussion; Missed Class=the number of days student athletes did not attend class due to the concussion; Accommodations Received=the type of accommodation the student athlete utilized while recovering from concussion. 